\title{
Unresectable Bone Sarcoma
}

National Cancer Institute

\section{Source}

National Cancer Institute. Unresectable Bone Sarcoma. NCI Thesaurus. Code C153072.

Bone sarcoma that is not amenable to surgical resection. 